\title{
The Co-Occurrence of Satisfaction and Frustration of Basic Psychological Needs and Its Relationship with Exercisers' Motivation
}

Filipe Rodrigues, Rita Macedo, Diogo Santos Teixeira, Luis Cid, Bruno Travassos, Henrique Neiva \& Diogo Monteiro

To cite this article: Filipe Rodrigues, Rita Macedo, Diogo Santos Teixeira, Luis Cid, Bruno Travassos, Henrique Neiva \& Diogo Monteiro (2021) The Co-Occurrence of Satisfaction and Frustration of Basic Psychological Needs and Its Relationship with Exercisers' Motivation, The Journal of Psychology, 155:2, 165-185, DOI: 10.1080/00223980.2020.1862738

To link to this article: https://doi.org/10.1080/00223980.2020.1862738

\section{Published online: 04 Feb 2021.}

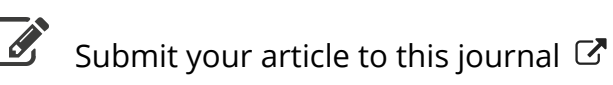

III Article views: 41

Q View related articles ¿

View Crossmark data $₫$ 


\title{
The Co-Occurrence of Satisfaction and Frustration of Basic Psychological Needs and Its Relationship with Exercisers' Motivation
}

\author{
Filipe Rodrigues $s^{a, b, c, d}$ (D), Rita Macedo ${ }^{e}$, Diogo Santos Teixeira ${ }^{f, g}$ (D) Luis Cid ${ }^{b, c}$ (D), \\ Bruno Travassos $^{a, c}$ (D), Henrique Neiva ${ }^{a, c}$, and Diogo Monteiro ${ }^{c, h}$ \\ anniversity of Beira Interior (UBI); ${ }^{b}$ Polytechnic Institute of Santarém Sport Sciences School of Rio Maior; \\ ${ }^{\mathrm{c}}$ Research Center in Sports Sciences Health and Human Development; ${ }^{\mathrm{d}}$ Life Quality Research Centre;

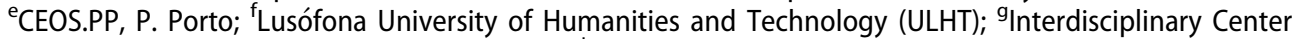

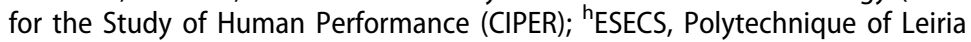

\begin{abstract}
Although the relationship between both need frustration and, particularly, need satisfaction and different motivational regulations for exercise has been widely examined in the literature, little is known about the co-occurrence of both need satisfaction and need frustration in the exercise context. Grounded in self-determination theory, the present study aimed to examine the effects of both need satisfaction and frustration on motivational regulations for exercise, by applying a response surface analysis approach. In total, 477 regular exercisers aged 18-54 years participated in this study. The interaction between needs (high on both need satisfaction and frustration) displayed a positive and significant association with amotivation, integrated regulation, and intrinsic motivation. Considering the direction of the discrepancy (high vs. low levels of need satisfaction and frustration) related to the behavioral regulations, results showed that higher need satisfaction relative to need frustration was associated with more self-determined regulations of motivation. Contrarily, higher need satisfaction relative to need frustration was associated with lower scores on amotivation, external, introjected, and identified regulation. Overall, these findings extend previous literature, suggesting that need satisfaction and frustration are distinct factors that can be experienced simultaneously in individuals during exercise and that different degrees of both needs have different associations with behavioral regulations.
\end{abstract}

\section{ARTICLE HISTORY}

Received 7 January 2020

Accepted 8 December 2020

\section{KEYWORDS}

Need satisfaction; need frustration; behavioral regulations; exercise; physical activity; response surface analysis

\section{Introduction}

One of the multiple benefits of exercise is the decrease of chronic disease risk, as well as the increase in longevity (Rhodes et al., 2017; Warburton \& Bredin, 2017). Additionally, not only does it positively impact our physics, but also increases psychological well-being and mental health (Biddle, 2016). Although it is widely acknowledged that regular exercise has major health benefits, a substantial number of adults do not meet the recommendations from the World Health Organization guidelines (Guthold 
et al., 2018; Loyen et al., 2016). Specifically, adults are less likely to engage in physical exercise compared to younger individuals, pointing out the lack of motivation as one of the major reasons (Eurobarometer, 2018). Thus, a key element underpinning regular physical exercise is motivation as it has been described in previous literature (Ntoumanis et al., 2020; Rodrigues et al., 2018; Teixeira et al., 2012).

Understanding the relationship between motivation and exercise behavior in adults is crucial given the positive association between regular exercise and positive health-related outcomes (Teixeira et al., 2012). Previous literature has identified the factors that support or undermine motivation, explaining that motivation is dependent on how basic psychological needs are met (Ryan \& Deci, 2017). While previous studies have measured need satisfaction and need frustration and examined their predictive validity on motivation (García-González et al., 2019; Rodrigues et al., 2020), to the best of our knowledge, none has ever focused on the effect of the interaction between need satisfaction and need frustration on behavioral regulation in the context of exercise using a response surface analysis approach. That is, literature is abundant on examining the independent association between needs and motivation, however, it is scarce on examining the cooccurring effect of needs (Warburton et al., 2020). The current study intends to investigate the relationship between the satisfaction and frustration of basic psychological needs and motivation, proposing a greater refinement of methods and SDT measures (Ryan \& Deci, 2019). More precisely, this study aims to examine the effects of both high versus low need satisfaction and need frustration as a co-occurring factor on motivational regulations for exercise, using a response surface analysis approach. The current study speaks to the concerns raised by Ryan and Deci (2020), by providing alternative statistical tests for examining motivations and perceived needs, exploring deeper and more complex associations which are overlooked with traditional statistical regression procedures.

\section{Theoretical Framework}

Self-determination theory (SDT) is a macro-theory of motivation that has been used to investigate motivation in several health-related behaviors (Ntoumanis et al., 2020). SDT explains human motivation based on social-contextual factors and personality aspects and states that humans are innately active and driven to achieve optimal growth and well-being (Ryan \& Deci, 2017). In the exercise context, SDT has received increased attention, and consequently, its use is encouraged in exercise-related research (Teixeira et al., 2012).

According to Deci and Ryan (2008), motivation can be characterized by the degree of self-determined behavior. Hence, motivation can be manifested differently and different types of motivation can explain much of human behavior (Ryan \& Deci, 2017). Different forms of motivation refer to specific regulations that exist along a motivational continuum of self-determined behavior (Howard et al., 2017). Amotivation stands as the least form of self-determined motivation, in which the individual acts on the behavior without intent or reason. As we progress along the continuum, external regulation arises referring to the endorsement of the behavior out of the desire for external rewards. Next on the continuum is introjected regulation, which refers to a person who 
engages in a specific behavior to seek approval or avoid shame. Identified regulation emerges as a more self-determined regulation in which the behavior is personally important to the individual, followed by integrated regulation, a form of motivation that arises when a person has fully integrated the behavior within himself. The most self-determined regulation is intrinsic motivation, which is linked to the interest and enjoyment that a person finds in an activity.

The extent to which motivation emanates from the self will impact cognitive, emotional, and behavioral outcomes (Ryan \& Deci, 2017). Self-determined forms of motivation are expected to predict positive outcomes, such as exercise persistence (Rodrigues et al., 2020), enjoyment (Teixeira et al., 2020), and other health-related outcomes (Ntoumanis et al., 2020). Contrarily, external and introjected forms of motivation and amotivation have shown to be positively associated with negative consequences such as exercise drop-out, lower intentions to engage in physical activity and other maladaptive outcomes (Teixeira et al., 2012).

The more internalized the extrinsic motivation, the more self-determined motivated the individual will be when engaging in a specific behavior (Ryan \& Deci, 2017). Thus, individuals extrinsically regulated can internalize and integrate the behavior over time, leading them to engage in the behavior for its own sake and not for external contingencies or self-imposed reasons. However, for this process to occur, individuals need to experience that their Basic Psychological Needs (BPN) are fulfilled, which has been consistently shown in previous research (Ryan \& Deci, 2017; Vansteenkiste \& Ryan, 2013).

\section{Basic Psychological Needs}

Grounded in SDT, it is theorized that optimal functioning is facilitated by the fulfillment of three basic psychological needs (Ryan \& Deci, 2017). These needs must be constantly satisfied for psychological growth, integrity and adaptive outcomes. The need for autonomy represents a sense of volition and self-endorsement, in which the person acts of own will. The need for competence represents the need to learn new skills and master the actual environment. The need for relatedness refers to the need to feel connected with others. While needs satisfaction have been measured substantially, Vansteenkiste and Ryan (2013) have conceptualized basic psychological need frustration as being an additional motivational determinant within the SDT universe that should be measured. The concept of needs frustration goes beyond a simple perception of low levels of autonomy, competence, and relatedness satisfaction. In the sport context, Bartholomew et al. (2011) proposed that low scores of needs satisfaction do not adequately capture the intensity of active needs frustration. These authors provide the example of athletes feeling incompetent because they cannot be effective (i.e. low levels of needs satisfaction) versus feeling incompetent because their coach is demanding (i.e. high levels of needs frustration). Thus, needs frustration is characterized by the perception that the needs are being actively thwarted (Bartholomew et al., 2011). In this regard, it is suggested that needs frustration would be more likely to lead to negative outcomes such as ill-being than low experiences of needs satisfaction (Bartholomew et al., 2011; Ryan \& Deci, 2017; Vansteenkiste et al., 2020). 
In this regard, satisfaction and frustration are not opposite, that is, needs frustration is not the mere lack of needs satisfaction, nor is need satisfaction experienced in the absence of need frustration (Bartholomew et al., 2011; Bhavsar et al., 2020; Gunnell et al., 2013). Vansteenkiste and Ryan (2013) argue that these constructs have an asymmetrical association such that low levels of needs satisfaction does not imply high levels of needs frustration. Recent advances in SDT research have shown that additional assessment of needs frustration is needed, to account for maladaptive outcomes (TóthKirály et al., 2020; Vansteenkiste et al., 2020; Warburton et al., 2020).

With respect to the associations between needs and behavioral regulations, in general they tend to follow the bright and dark side of motivation pattern (Ryan \& Deci, 2017). That is, need satisfaction tends to be positively associated with more self-determined motivations, while need frustration tends to be positively associated with controlled forms of motivation and amotivation (Ryan \& Deci, 2017). Several theoretical and empirical studies are consistent with this assumption as they tend to display these associations (e.g. García-González et al., 2019; Rodrigues et al., 2018; Teixeira et al., 2012; Tóth-Király et al., 2020; Vansteenkiste \& Ryan, 2013).

While these are general assumptions, some studies have found contradictory results or have shown that this pattern is not always straightforward. On measuring needs in exercisers, Rodrigues et al. (2020) reported that exercisers' needs satisfaction and needs frustration were positively associated with introjected regulation, which is a controlled form of motivation. On the other hand, Deci and Ryan (2008) have stated that controlled forms of motivation could be accounted for competence and relatedness satisfaction, depending on the degree (high vs. low) of need fulfillment. One study conducted by Bidee et al. (2016) found that initial level of need satisfaction (but not slope of need satisfaction) predicted changes in autonomous motivation, However, initial level of need frustration at the slope of need frustration did not predicted changes in controlled motivation. In this regard, this distinction is hard to instrumentalize, as there are few evidences in the exercise context as to which type of motivation is represented by participant's feeling of needs satisfaction and needs.

Warburton et al. (2020) provided further understanding on the associations between needs and several outcomes, by performing a latent cluster analysis based on needs satisfaction and frustration in two different physical activity contexts (i.e. physical education and leisure-time physical activity). In the physical education sample, three groups emerged: low need satisfaction/high need frustration; high need satisfaction/low need frustration; and, moderate on both needs. Results from the study conducted by Warburton et al. (2020) showed that there were significant differences between groups on the different behavioral regulations, where the high need satisfaction/low need frustration displayed the highest mean, followed by the group with moderate on both needs on self-determined motivations. In the sample of athletes, four groups emerged in the Warburton et al. (2020) study: low need satisfaction/high need frustration; high need satisfaction/low need frustration; moderate need satisfaction/low need frustration; and, moderate need satisfaction/high need frustration. While other outcomes were considered (e.g. enjoyment, burnout, well-being), similar patterns appeared compared to the student sample, where high needs satisfaction and low need frustration displayed significant differences compared to the other groups on enjoyment (one of the definitions of 
intrinsic motivation) and well-being. Low needs satisfaction and high needs frustration displayed significant differences compared to groups with high or moderate needs satisfaction and low needs frustration.

\section{Past Research}

As described earlier, needs satisfaction and frustration may not be dichotomic responses, but may cohabit in the same individual (Vansteenkiste et al., 2020). Warburton et al. (2020) have called for more research in other domains to corroborate and extend the findings on the differentiation between needs satisfaction and needs frustration. As stated, "it is important to consider the combined associations of need satisfaction and need frustration since there is evidenced of a protective effect of experiences of need satisfaction when individuals experienced need frustration" (Warburton et al., 2020, p. 11). These authors used a person-centered analysis to identify groups based on their experiences of needs and proposed future avenue to examine the distinctiveness between them. Thus, the examination of both needs satisfaction and frustration is still underresearched. Specifically, the interaction of needs satisfaction and needs frustration requests more investigations since literature speculates that the product between them could be associated to both autonomous or controlled forms of motivation, depending on the levels of satisfaction and frustration experience (Rodrigues et al., 2019; Teixeira, Silva, et al., 2018). We propose a different approach to that taken by Warburton et al. (2020) to examine the differentiation between needs.

The lack of literature regarding the interaction of both needs on different outcomes could rely on the limitations of studies using traditional statistical regression procedures. Conventional regression analyses provide a two-dimensional view of the relationships between predictor and outcome variable. In addition, with traditional regression analysis, one cannot assess whether there is a non-linearity and a product relationship along the line of agreement between two independent variables related to the dependent variable (Shanlock et al., 2010).

One innovative method to approach these statistical limitations is by using a Response Surface Analysis (RSA) approach proposed by Edwards (2007). RSA is a useful method in analyzing associations of two independent similar but distinct variables on predicting a dependent variable (Atwater et al., 1998). By using RSA, researchers can analyze the degree of agreement, the degree of discrepancy, and the direction of discrepancy between independent variables on the outcome under analysis (Edwards, 2007). Hence, this methodological procedure seems to be a fashionable approach to analyze the independent, as well as the interaction effect of both need satisfaction and need frustration on behavioral regulations.

\section{Current Research}

Given the importance of exercise motivation, identifying the key role of need satisfaction and need frustration and their interaction effect may provide important evidence on how to base interventions to increase self-determined motivation, and consequently, promote exercise participation on the long-term (Ntoumanis et al., 2017). Moreover, no 
studies have been conducted considering both types of needs in the exercise context, except in the sport and physical activity domain (Warburton et al., 2020) using a latent profile analysis. Although the relationship between both need frustration and, particularly, need satisfaction and different motivational regulations for exercise has been widely examined in the past (Rodrigues et al., 2018; Teixeira et al., 2012), little is known about the co-occurrence of both need satisfaction and need frustration in the exercise context. Grounded in SDT, this is the first study that aimed to examine the effects of both need satisfaction and need frustration on motivational regulations for exercise, using an RSA approach. This study aims to show whether basic need satisfaction and frustration are distinct and if they can be experienced simultaneously.

This study employs an RSA approach to identify the congruence effect between need satisfaction and need frustration on behavioral regulations. Based on previous literature, it was anticipated that low levels of need satisfaction and high levels of need frustration would be related to non-self-determined regulations and amotivation, since the experience of being thwarted by the social context is related to controlled motivational regulations (Rodrigues et al., 2018). Low levels of need frustration and high need satisfaction would be related to more self-determined regulations, since the satisfaction of autonomy, competence, and relatedness has consistently been reported as the most proximal determinant of adaptive motivation (Ryan \& Deci, 2017). In addition, Warburton et al. (2020) have shown significant differences between students with high need satisfaction/ low need frustration and students with the opposite degree of needs (low satisfaction and high frustration) and intrinsic motivation, which supports our previous hypotheses. At last, it was hypothesized that high levels of both needs (interaction effect) would be positively associated with self-determined regulations, since need satisfaction could display a protective effect against the negative role of need frustration (Warburton et al., 2020).

\section{Methods}

\section{Design and Participants}

This study employed a cross-sectional design. In total, a convenience sample of 477 regular exercisers (220 females; 257 males) in gym and health clubs aged 18-54 years $(M=34.13 ; S D=12.02)$ participated in this study. Self-reported exercise frequency ranged from 2-5 times per week $(M=2.57$; $S D=.98)$ and most reported fitness activities were fitness group class $(45.3 \%)$ and cardio-weightlifting workout $(54.7 \%)$. To be eligible for this study, potential participants needed to be at least 18 years of age, have at least three months of exercise experience and train at least 2 times per week.

\section{Measures}

The Basic Psychological Need Satisfaction and Frustration Scale in Exercise Portuguese version (Rodrigues et al., 2019) was used to examine the participants' experience of need satisfaction and need frustration. This scale comprises six factors (3 items for each factor: autonomy satisfaction and frustration, competence satisfaction and frustration, and relatedness satisfaction and frustration), in which participants replied to 24 items 
on a 5-point scale anchored from 1 ("totally disagree") to 5 ("totally agree"). Composite scores for need satisfaction and need frustration were calculated according to previous assumptions (Bartholomew et al., 2011; Bhavsar et al., 2020).

The Behavioral Regulation in Exercise Questionnaire Portuguese version (Cid et al., 2018) was used to assess different types of motivations based on SDT. This scale measures amotivation (e.g. "I do not know why I exercise"), external regulation (e.g. "People tell me I need to exercise"), introjected regulation (e.g. "I feel guilty when I skip training session"), identified regulation (e.g. "It is important for me to exercise regularly"), integrated regulation (e.g. "Exercise is aligned with my personal objectives") and intrinsic motivation (e.g. "I like my training sessions"). Participants answered to 18 items using a 5-point scale ranging from 0 ("strongly disagree") to 4 ("strongly agree").

\section{Procedures}

Ethical approval was obtained before data collection (reference number: CE-UBI-pJ2018-044:ID683) for this study. Additionally, data collection procedures were conducted in accordance with the Helsinki Declaration and its later amendments. The authors contacted gym managers to obtain permission to conduct this research. After approval, potential participants were contacted at reception desk and were asked to participate voluntary in this study. Researchers explained the study objectives and informed consent was obtained for each exerciser individually. Data were collected before training session and time taken to fill the multi-section survey was approximately $15 \mathrm{~min}$.

\section{Statistical Analysis}

\section{Preliminary Analysis}

A preliminary analysis on the descriptive data was performed using the software SPSS Statistics (IBM Corporation, 2017). Composite reliability coefficients were used to assess the internal consistency of the measures, with scores greater than 0.70 considered as acceptable (Raykov et al., 2016). The Pearson bivariate correlations between measures were examined to determine the intensity and direction.

\section{Response Surface Analysis}

The RSA was performed using Mplus 7.4 (Múthen \& Múthen, 2010). We used RSA to test the effect of agreement and disagreement among needs on behavioral regulations. This statistical approach allows for a combination of two relatable but distinct variables to an outcome while retaining information about the differences between the predictor variables (Edwards, 2007). Need satisfaction and need frustration were set as predictor variables, and RSA analysis was conducted one for each of the six behavioral regulations proposed by SDT.

For RSA, the polynomial regressions were performed on scale-centered variables $\left(b_{1}+\right.$ $b_{2}$ ) to facilitate the interpretation of the findings (Edwards, 2007) and to reduce possible multicollinearity issues (Cohen et al., 2003). Afterwards, for the non-linear relationship, the centered variables were squared $\left(b_{3}+b_{5}\right)$. Finally, the interaction of both need groups was calculated $\left(b_{4}\right)$. Unstandardized coefficients and errors, and covariances 
Table 1. Surface Tests, Formulas, Meaning, and Interpretation.

\begin{tabular}{|c|c|c|c|}
\hline Value & Formula & Meaning & Interpretation \\
\hline$a_{1}$ & $b_{1}+x_{2}$ & $\begin{array}{l}\text { Reflects the linear relationship } \\
\text { between the agreement of } \\
\text { need satisfaction and } \\
\text { frustration }\end{array}$ & $\begin{array}{l}+a_{1}=\text { as the degree of agreement between need } \\
\text { constructs increases so does the outcome; }-a_{1}=\text { as the } \\
\text { degree of agreement between need constructs } \\
\text { decreases so does the outcome }\end{array}$ \\
\hline$a_{2}$ & $b_{3}+b_{4}+b_{5}$ & $\begin{array}{l}\text { Reflects the non-linear } \\
\text { relationship between the } \\
\text { degree of agreement of need } \\
\text { satisfaction and frustration }\end{array}$ & $\begin{array}{l}+a_{2}=\text { the effect of agreement between need constructs } \\
\text { becomes more pronounced at higher levels of } \\
\text { agreement; }-a_{2}=\text { the effect of agreement between } \\
\text { need constructs diminishes at higher levels of agreement }\end{array}$ \\
\hline$a_{3}$ & $b_{1}-b_{2}$ & $\begin{array}{l}\text { Reflects how the direction of the } \\
\text { differentiation of need } \\
\text { satisfaction and frustration }\end{array}$ & $\begin{array}{l}+a_{3}=\text { higher need satisfaction relative to need frustration } \\
\text { is associated with higher scores on the outcome; }-a_{3}= \\
\text { higher need satisfaction relative to need frustration is } \\
\text { associated with lower scores on the outcome }\end{array}$ \\
\hline$a_{4}$ & $b_{3}-b_{4}+b_{5}$ & $\begin{array}{l}\text { Reflects how the degree of } \\
\text { differentiation in need } \\
\text { satisfaction and frustration }\end{array}$ & $\begin{array}{l}+a_{4}=\text { a greater positive differentiation between need } \\
\text { constructs (i.e., satisfaction is higher than frustration) is } \\
\text { associated with higher scores on the outcome; }-a_{4}=a \\
\text { greater positive differentiation between need constructs } \\
\text { (i.e., satisfaction is lower than frustration) is associated } \\
\text { with lower scores on the outcome }\end{array}$ \\
\hline
\end{tabular}

between all five predictors were imputed to compute the surface tests (Shanlock et al., 2010).

As the quadratic regressions with these variables imply a three-dimensional surface representing the associations between them, response surface tests provide means for estimating and interpreting its direction and shape (Edwards, 2007). Hence, the surface scores are plotted in graphs which are interpreted. The four surface scores represent the slopes and curvature of two lines. The first line runs diagonally from the nearest to the farthest corners of the graph. This is called the line of perfect agreement $\left(a_{1}\right)$ as it represents how the agreement (e.g. high on both needs) between predictors relate to the outcome. The second surface test $\left(a_{2}\right)$ is the curvature and shows whether this relationship (between needs and behavioral regulation) is linear or non-linear, that is, if the behavioral regulations differ depending on whether the ratings are high and in agreement or low and in agreement between needs. The second line runs diagonally from the right to the left corner of the graph and it is called the line of incongruence. The third surface test $\left(a_{3}\right)$ represents the slope and the fourth test $\left(a_{4}\right)$ the curvature. Comparable to the line of perfect agreement, the curvature shows how disagreement between predictors (e.g. high on needs satisfaction and low on needs frustration) relates to the outcome and the slope if the direction matters.

\section{Results}

\section{Preliminary Analysis}

Missing data was found in five participants and data were therefore imputed using hierarchical regression procedures. The means, standard deviations, composite reliability coefficients, and correlations among variables are presented in Table 1. Looking at means, exercisers reported higher levels of need satisfaction and autonomous forms of motivation, compared to need frustration and controlled forms of motivation and amotivation. Results also showed normal distribution, since skewness and kurtosis were 


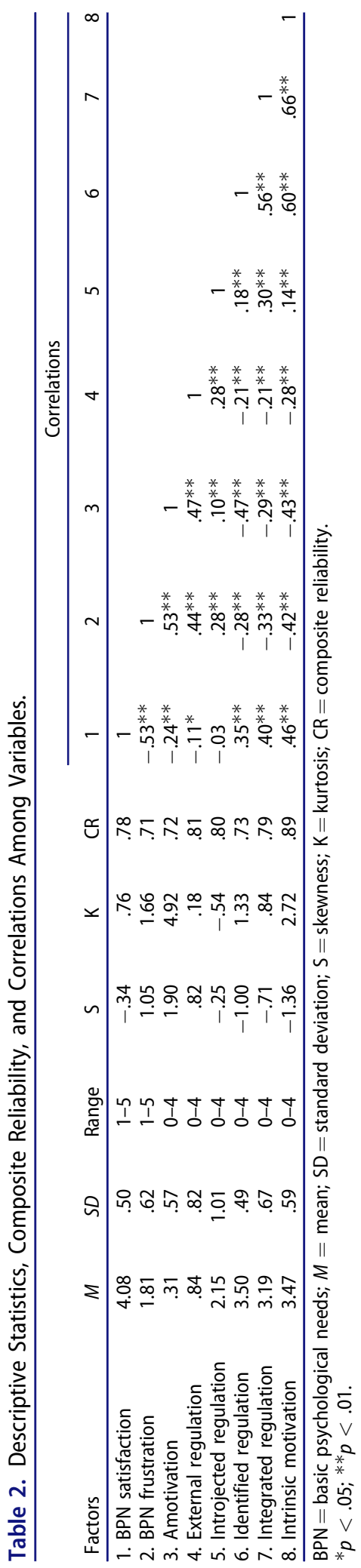


Table 3. Polynomial Regression Analyses and Surface Values for the Needs Satisfaction and Needs Frustration.

\begin{tabular}{|c|c|c|c|c|c|c|}
\hline Model & Amotivation & $\begin{array}{l}\text { External } \\
\text { regulation }\end{array}$ & $\begin{array}{c}\text { Introjected } \\
\text { regulation }\end{array}$ & $\begin{array}{l}\text { Identified } \\
\text { regulation }\end{array}$ & $\begin{array}{l}\text { Integrated } \\
\text { regulation }\end{array}$ & $\begin{array}{c}\text { Intrinsic } \\
\text { motivation }\end{array}$ \\
\hline \multicolumn{7}{|l|}{ Polynomial regression } \\
\hline Needs satisfaction centered (b1) & -.02 & $.18^{*}$ & $.29 *$ & $.28^{*}$ & $.40^{*}$ & $.33^{*}$ \\
\hline Needs frustration centered (b2) & $.36^{*}$ & $.62^{*}$ & $.60^{*}$ & -.08 & $-.22^{*}$ & $-.29^{*}$ \\
\hline Needs satisfaction squared (b3) & -.06 & -.15 & .01 & $.11^{*}$ & .13 & .05 \\
\hline Interaction between needs (b4) & $.11^{*}$ & .08 & .11 & .08 & $.19^{*}$ & $.16^{*}$ \\
\hline Needs frustration squared (b5) & $.20^{*}$ & .07 & -.05 & -.01 & .07 & .07 \\
\hline Explained variance $\left(R^{2}\right)$ & .34 & .21 & .11 & .13 & .21 & .26 \\
\hline \multicolumn{7}{|l|}{ Surface tests } \\
\hline$a_{1}=\left(b_{1}+b_{2}\right)$ & $.34^{*}$ & $.80^{*}$ & $.89^{*}$ & $.21^{*}$ & .18 & .05 \\
\hline$a_{2}=\left(b_{3}+b_{4}+b_{5}\right)$ & $.25^{*}$ & .00 & .07 & .18 & $.39 *$ & $.28^{*}$ \\
\hline$a_{3}=\left(b_{1}-b_{2}\right)$ & $-.38^{*}$ & $-.44^{*}$ & $-.31^{*}$ & $.36^{*}$ & $.62^{*}$ & $.62^{*}$ \\
\hline$a_{4}=\left(b_{3}-b_{4}+b_{5}\right)$ & .15 & -.16 & -.15 & .02 & .13 & -.04 \\
\hline
\end{tabular}

$R^{2}=$ explained variance.

$* p<0.05$.

contained within cutoffs. For all measures, reliability coefficients were above cutoff criteria of .70, indicating acceptable internal consistency.

Bivariate correlations showed a positive and significant correlation between need satisfaction and autonomous motivation forms (i.e. intrinsic motivation, integrated regulation, and identification regulation), and a negative and significant correlation between need frustration and controlled motivation forms (i.e. introjected regulation and external regulation) for a better understanding of the results. Moreover, need frustration displayed a positive and significant correlation with controlled forms of motivation and amotivation, and showed a negative and significant correlation with all forms of autonomous motivation. Need satisfaction did not display any significant association with introjected regulation. For detailed information see Tables 1-3.

\section{Response Surface Analysis}

The range of explained variance varied between $11 \%$ in introjected regulation and $34 \%$ in amotivation. The surface values on the relationship between needs and behavioral regulations show that, as the degree of agreement between need satisfaction and frustration increased, so did amotivation, external, introjected, and identified regulation. As seen in Figures 1-4, the ratings on these behavioral regulations increase along the line of perfect agreement, from the front corner to the back. In addition, the lowest values on these regulations are at the front of the graph, where both need satisfaction and need frustration are low.

The effect of agreement between needs became more noticeable at higher levels of agreement, predicting more amotivation, integrated regulation, and intrinsic motivation. These findings suggest that the agreement between needs matters, as surface value $a_{2}$ was significant. From Figures 1, 5 and 6, it is possible to observe a more convex surface, indicating that behavioral regulations could increase or decrease more sharply as both need satisfaction and need frustration become lower or higher at some point.

Considering the direction of the discrepancy between needs related to the outcome, results show a significant negative surface value $\mathrm{a}_{3}$ on amotivation and controlled forms of motivation. That is, these behavioral regulations are relatively high when need 


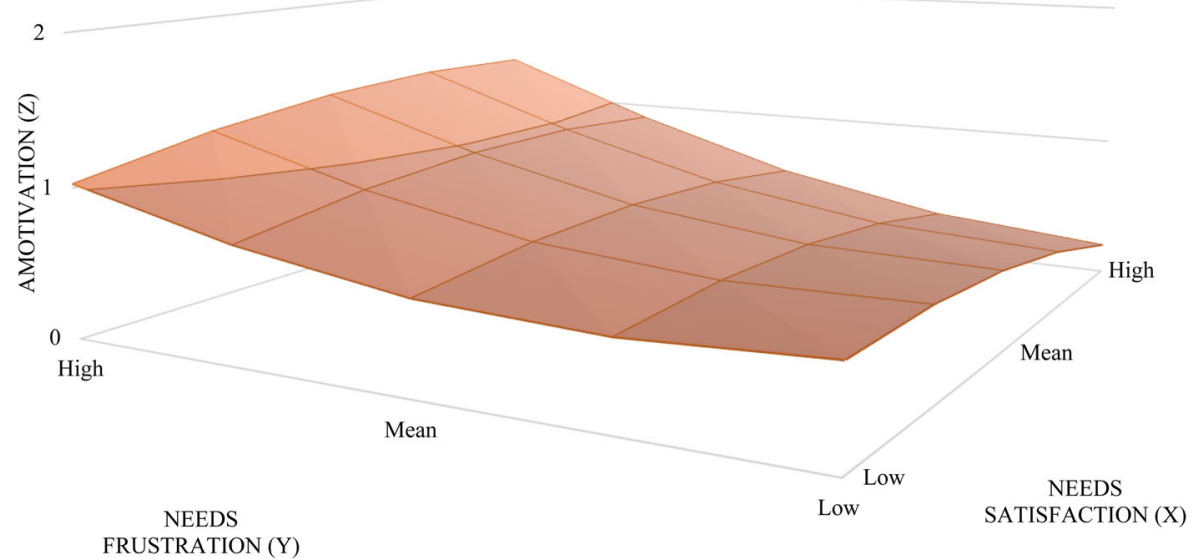

Figure 1. Need satisfaction and needs frustration on amotivation.

3

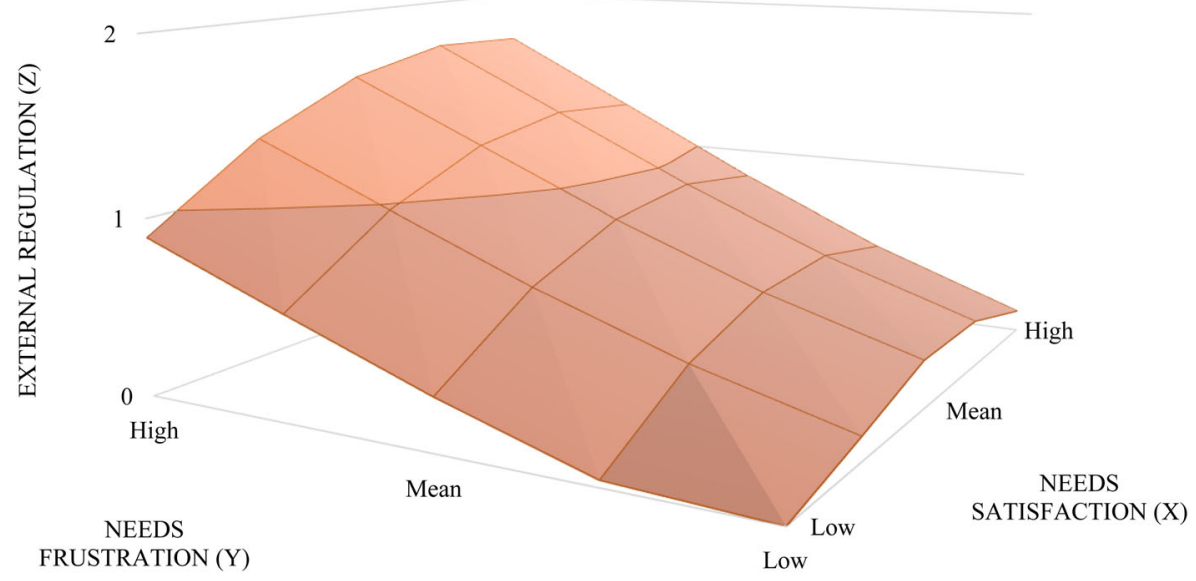

Figure 2. Needs satisfaction and needs frustration on external regulation.

frustration was higher than need satisfaction (see Figures 1-3). This is represented by the left corner of the graphics being higher compared to the right corner. On the other hand, autonomous forms were still high when exercisers need satisfaction was high and low on need frustration. As shown in Figures 4-6, the right corner is higher compared to the left corner. Last, looking at the degree of discrepancy between needs on behavioral regulations (surface value $\mathrm{a}_{4}$ ), no significant results emerged. Thus, a greater positive and significant differentiation between need constructs was not associated with significant higher or lower scores on the outcome. 
3

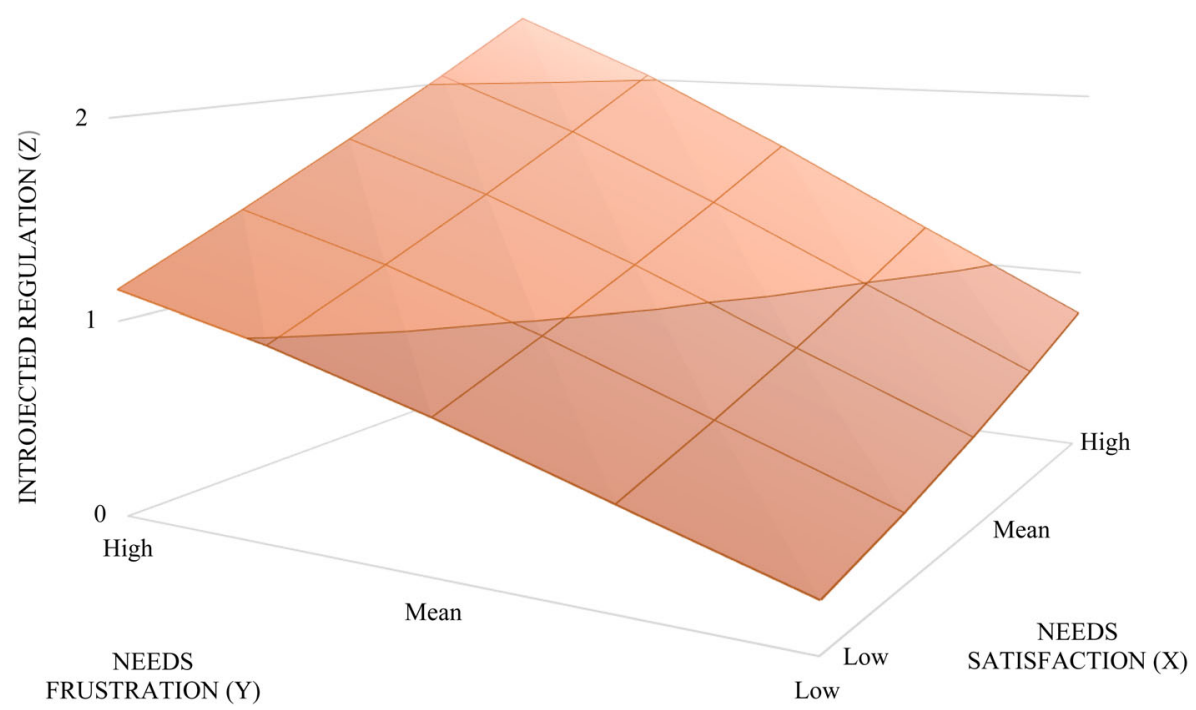

Figure 3. Needs satisfaction and needs frustration on introjected regulation.

3

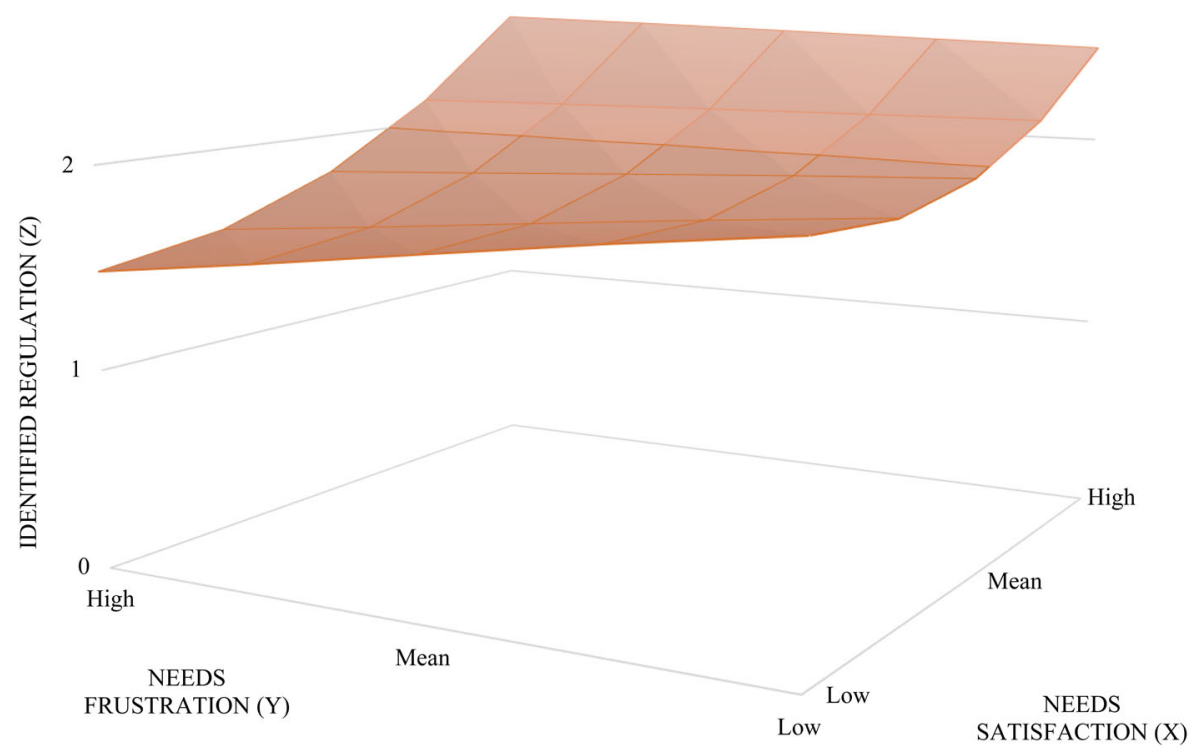

Figure 4. Needs satisfaction and needs frustration on identified regulation.

\section{Discussion}

Grounded in SDT, the present study aimed to examine the effects of both need satisfaction and need frustration on motivational regulations for exercise, using a response surface analysis approach. Present results offer important new insights, since the 
3

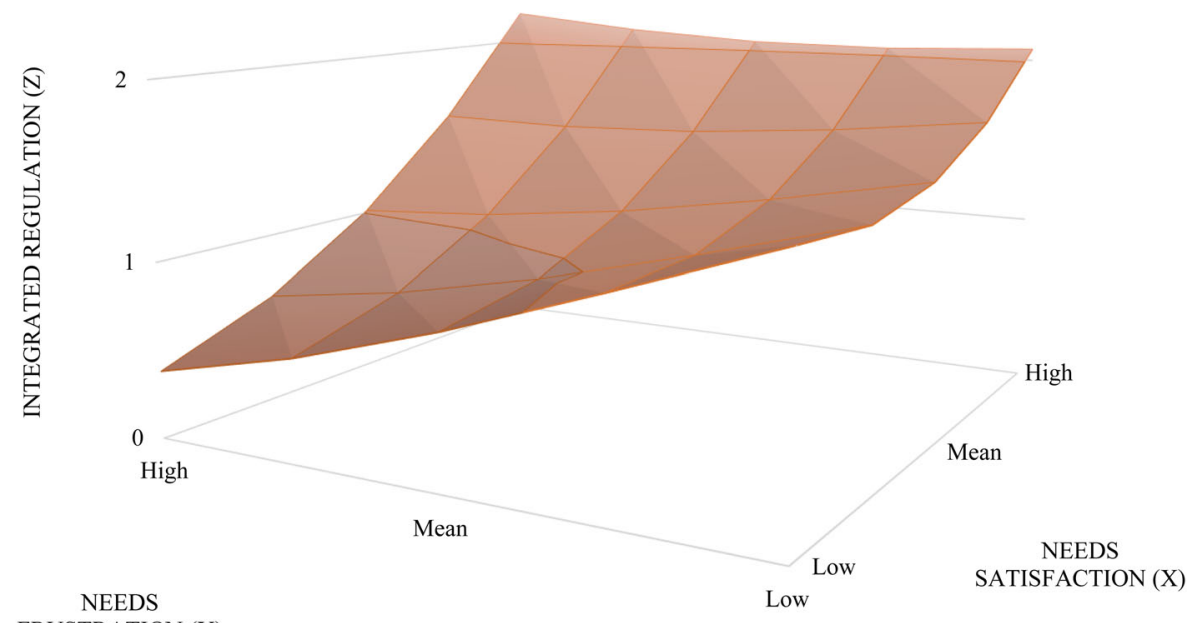

FRUSTRATION (Y)

Figure 5. Needs satisfaction and needs frustration on integrated regulation.

3

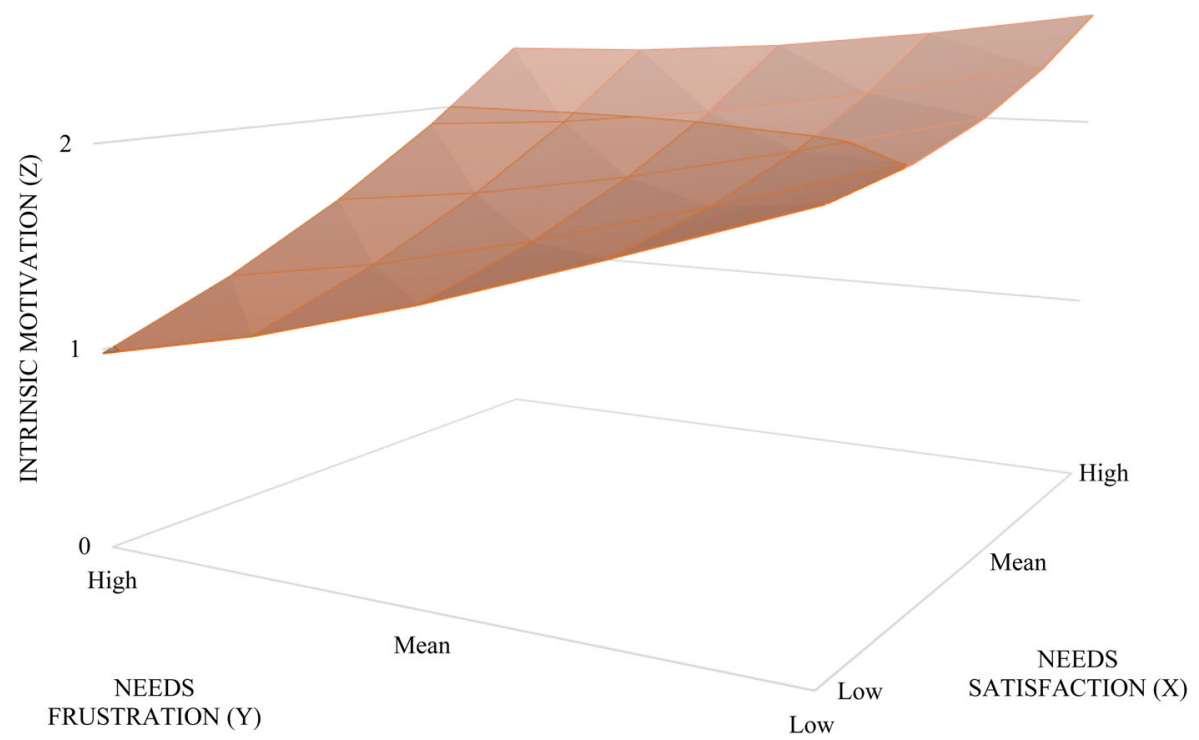

Figure 6. Needs satisfaction and needs frustration on intrinsic regulation.

co-occurrence of both need satisfaction and need frustration is still unclear as stated by Warburton et al. (2020), and in the context of exercise research is limited. Current results propose that it is essential for researchers and professionals to assess both need satisfaction and need frustration, as they play different roles on motivation.

The surface values showed that increased levels of agreement between needs constructs (high levels of need satisfaction and need frustration) are related to increased 
levels of amotivation, controlled forms of motivation, and even identified regulation. These results are somewhat inconsistent with past research which has stated that needs satisfaction would have a negative relationship with amotivation and controlled forms of motivation (Costa et al., 2015; Ryan \& Deci, 2017). Nonetheless, current results are relatable to those shown by Haerens et al. (2015), in which need satisfaction positively predicted controlled forms of motivation in a sample of college students. The positive association between need satisfaction and non-self-determined regulations and amotivation in exercisers could be influenced by the specific association between competence satisfaction and extrinsic regulations. It is somewhat consistent with the assumption in SDT that competence need satisfaction is an essential yet insufficient condition to foster internalization and self-determined motivation (Ryan \& Deci, 2017). That is, in isolation from the other two needs, the need for competence may result only in partial internalization where the individual only feels competent to engage in physical exercise. For participants to obtain full internalization of exercising and even self-determined motivation, they ideally need to experience some sort of volitional choice (autonomy satisfaction) and supported by others (relatedness satisfaction) in combination with competence (Ryan \& Deci, 2017). Hence, feeling competent and mastering new set of skills during training may provide partial explanation as to why individuals engage in exercise for controlled motivations. These results reinforce the notion that low need satisfaction is distinct from high need frustration, having differentiated effect on motivation (Bartholomew et al., 2011; Haerens et al., 2015; Warburton et al., 2020).

The effect of need constructs became more noticeable at higher levels of agreement, predicting also amotivation, integrated regulation, and intrinsic motivation, indicating that these behavioral regulations could increase or decrease more sharply as both need satisfaction and need frustration become lower or higher at some point. However, scores obtained in this study are only significant if there was likewise significant interaction between constructs on these behavioral regulations. These results corroborate with Vansteenkiste and Ryan (2013), showing that individuals need to feel some sort of frustration in order to promote changes on different behaviors and internalization mechanisms, provided that need satisfaction is experienced. Current results suggest that experiencing need frustration within a context may prevent high need satisfaction being experienced. For example, when individuals feel that they are incompetent or unable to connect with others during physical exercise, this does not indicate higher expression of need frustration but rather the feeling of unsatisfied needs or low need satisfaction. For example, in the study conducted by Warburton et al. (2020) in a sample with athletes, when need frustration was moderate or high, only low or moderate levels of need satisfaction were experienced, whereas when need frustration was not experienced, need satisfaction was experienced to at least moderate levels. Contrarily, when individuals experience high need satisfaction, this could impose some influence on the degree of need frustration. Warburton et al. (2020) found that when the feeling of need satisfaction was moderate, experiences of need frustration appeared to be less detrimental to the outcomes reported by the athletes. While similar patterns emerge in current analysis of needs as co-occurring determinants of motivation, the interplay between needs seem to differ according to the context. 
Last, higher levels of need satisfaction relative to need frustration was associated with higher scores on autonomous forms of motivation, whereas contrary results were indicative of controlled forms of motivation and amotivation. High levels of need frustration and low experience of need satisfaction lead to additional significant association with amotivation and controlled forms of motivation (see corner in the left of Figures 1-3), but not when exercisers report high need satisfaction and low need frustration. Contrarily, exercisers rating high levels of need satisfaction continued to be significantly associated with integrated regulation and intrinsic motivation (see corner in the right of Figures 4 and 6) even when need frustration was low. These results support previous studies on the associations of need satisfaction and need frustration on motivation in exercisers (Rodrigues et al., 2018) as well as in other physical activity related context (Haerens et al., 2015).

The differences between low need satisfaction and need frustration have been described by Bartholomew et al. (2011), who pinpointed that experiencing low levels of need satisfaction was qualitatively different to experiencing need frustration. Results from this study are consistent with this assumption. Such an experience might be the result of the exerciser's inability to learn and master a new set of moment or exercises, or because he had been subjected actively to feel incompetent by fitness trainers and peers. According to the conceptualization proposed by several authors (Bartholomew et al., 2011; Vansteenkiste \& Ryan, 2013), the former would be a case of low competence satisfaction and the latter would be a case of competence frustration. Through this dual-process model, scholars have demonstrated need frustration to be a stronger predictor of maladaptive outcomes relative to low need satisfaction (Bartholomew et al., 2011). In this regard, it is important to differentiate between a lack of need satisfaction also described as need dissatisfaction (e.g. unable to feel connected with others) and experiences of need frustration (e.g. perceptions exclusion by significant others) as stated by Cheon et al. (2019).

Current results present new knowledge on the agreement effect of both needs on behavioral regulations based on SDT that could not be explained by past research using traditional regression procedures or person-centered analyses. This is related with the fact that previous research has focused only on the independent effect of both needs constructs on autonomous and controlled forms of motivation (Costa et al., 2015; Teixeira, Marques, et al., 2018). New approaches like RSA or person-centered profile analysis could explain in more detail how high/low experience of both type of needs are associated with motivation and other psychological outcomes. Current research also provides further support of need satisfaction and need frustration as distinct and cooccurring factors based on the SDT framework.

\section{Limitations and Agenda for Future Research}

There are some limitations related to the present study that should be considered. Firstly, this study was conducted with a convenience sample of Portuguese exercisers. Although basic psychological needs are said to be innate to all human beings (Ryan \& Deci, 2017), we cannot generalize these results to other domains and cultures. Thus, more research is needed to confirm if the associations persist across groups with 
different characteristics, and examine possible moderator variables (e.g. age, gender, cultural background). Secondly, the current study examined needs as composite scores. Future studies should test each need independently on different behavioral regulations to examine possible relationships that have not been accounted for in the current research. It would be interesting to see the relationships between competence satisfaction and competence frustration and controlled forms of motivation, since competence could have a positive effect on these forms of motivation (Deci \& Ryan, 2008). Thirdly, the cross-sectional design prevents us from answering the notion of causality. Forthcoming studies should assess needs and motivation over time, to examine the possible internalization effect. That is, individuals engaging in exercise due to controlled reasons, could, over time, internalize the behavior and exercise regularly based on conscious values. which are personally important for the individual (Ryan \& Deci, 2017). Lastly, an avenue of future research could be the assessment of the relationship between interpersonal behaviors and both need satisfaction and frustration in exercisers and fitness professionals. For example, one study found that the association between trainerathletes is not straightforward, meaning that some coaches may be inclined to be overly positive about their behaviors relative to what their athletes perceive suggesting that as many as 30\% of coaches may do this (Rocchi \& Pelletier, 2018). These discrepancies related to perceived interpersonal behaviors between trainer and athletes can have significant implications on how athletes experience need satisfaction and frustration as stated by Rocchi and Pelletier (2018).

\section{Theoretical and Practical Implications}

The findings in the current study have several implications for both research and practice in the context of exercise. From a theoretical perspective, our findings support the distinctiveness of need satisfaction and need frustration (Warburton et al., 2020). Additionally, we extent past literature by showing that exerciser experience of both types of needs represent distinct forms of motivation (Ryan \& Deci, 2017; Vansteenkiste et al., 2020). Based on SDT framework, our findings suggest that autonomous forms of motivation are the extent to which exercisers experience autonomy, competence, and relatedness satisfaction. Even in situations in which exercisers also experience high level of need frustration, need satisfaction could present a protective effect.

Although the selection of the statistical methods is dependent on the objective of the study, current research has illustrated the beneficial use of RSA in exercise-related research. Current findings suggest that RSA is a sophisticated statistical analysis that can be used on assessing asymmetrical constructs and their associations with a given outcome, which allows the examination of a three-dimensional relationship rather than only a two-dimensional association (Edwards, 2007). RSA made it possible to detect curvilinear relationships, and how levels on need satisfaction and need frustration mattered if ratings were in agreement or not.

From a practical point-of-view, current results suggest that, intervention strategies aimed at increasing exercise participation should be focused on increasing more autonomous forms of motivation, by targeting variables related to higher levels of need satisfaction and lower experience of needs frustration. Fitness instructors should endorse 
need-supportive behaviors when interacting with exercisers by providing them with clear rationale and meaningful exercise options, trying to understand their perspective of exercising, and encouraging self-initiation. Exercisers should be encouraged to improve their technique and receive some volitional choice of which exercises to perform. Fitness instructors ought to design training sessions so that mastery is the dominant experience for exercisers to experience competence satisfaction. In addition, these professionals should convey respect for the exercisers, so that they feel valued and significant, consequently experiencing higher relatedness satisfaction. By contrast, fitness instructors' controlling or need-thwarting behaviors ought to be much less pronounced. Hence, exercisers would experience less need frustration, being an indication of more self-determined motivations. Therefore, providing fitness professionals with need-supportive behaviors and strategies to avoid need-thwarting behaviors aimed at improving psychological need satisfaction and reducing thwarting are advised (Ntoumanis et al., 2017).

\section{Conclusion}

In sum, the current study underscores the importance of examining exercisers' needs and motivation using an RSA approach. Examining how the levels of needs combined allowed us to identify different results, in which need satisfaction can have a "protective effect" against the negative effect of need frustration. Specifically, individuals presenting high levels of need frustration can still endorse in exercise based on volitional choice if they still experience high levels of competence and relatedness satisfaction.

Current research offers an initial demonstration of how need satisfaction and need frustration are distinct constructs that co-occur in exercisers. Specifically, this study demonstrated that the levels of agreement and differentiation of both need constructs are associated with all behavioral regulations in a way that generally matches past literature on SDT. However, this is only exhibited using contemporary statistical procedures such as RSA. This underscores the importance of considering innovative statistical approaches that can analyze both need constructs, in order to understand the effect on motivation.

\section{Approval}

Approval from the Ethical Committee of Beira Interior University (CE-UBI-pJ-2018044:ID683) was obtained.

\section{Disclosure statement}

The authors declare no conflict of interest.

\section{Funding}

This work was supported by the National Funding through the Portuguese Foundation for Science and Technology, I.P., under the project UID04045/2020 for the authors Luís Cid, Bruno Travassos, Henrique Neiva, and Diogo Monteiro; and under the project UIDP/04748/2020 for the author Filipe Rodrigues. 


\section{Author notes}

Filipe Rodrigues is a researcher at the CIEQV and lecturer at Sports Science School of Rio Maior (ESDRM - IPSantarem) and his research focuses on motivational and cognitive theories to under- stand health-related behavior change in diverse domains.

Rita Macedo is a researcher in the field of social sciences, focusing on health-related outcomes and correlates of cultural differences. Her areas of interest are green product purchase, environmental and health concerns as well as the determinants of positive psychological consequences.

Diogo S. Teixeira is a young professor and researcher with a multidisciplinary background and professional practice in several areas of his academic training. He has a degree in Physical Education and Sport; a postgraduation degree in Health, Nutrition, and Exercise; a master's degree in Exercise and Wellness; and a PhD degree in Physical Activity and Health. His research focuses on motivational and emotional determinants and their relationship with the quality of practice in several health and sport contexts.

Luis Cid, PhD in Sport Sciences (since December 2010), is a professor at the Sport Science School of Rio Maior of the Polytechnic Institute of Santarem (since September 2004) and a senior researcher of the Research Center in Sport, Health and Human Development (since January 2011). Currently, he is the director of the School (since December 2018). Previously he was the subdirector of the school (April 2015-November 2018) and Scientific Coordinator of sports and exercise psychology department (March 2014-April 2018). His academic research field is linked to motivational determinants in sport, physical activity, and healthy lifestyles.

Bruno Travassos has a $\mathrm{PhD}$ in Sport Sciences and is a professor at University of Beira Interior. $\mathrm{He}$ is integrated member of CIDESD - Research Center in Sport Sciences, Health Sciences and Human Development and Portugal Football School from Portuguese Football Federation. His main research interests are focused on players' tactical behavior and performance, design and manipulation of practice tasks and career development and transition of football players.

Henrique Neiva concluded his degree in Sport and Physical Education in the Faculty of Sport of University of Porto (2008). In 2015, he finished PhD in Sport Sciences at the University of Beira Interior and Research Center in Sport Sciences, Health Sciences and Human Development. Neiva is a member of research Center in Sport Sciences, Health Sciences and Human Development and collaborates with University of Beira Interior. In the last years, he produced more than 50 scientific documents and reviewed several peer reviews papers in high-ranked journals.

Diogo Monteiro is a $\mathrm{PhD}$ in Sports Science. He has a degree in Sport and Exercise Psychology and master's degree in Sport and Exercise Psychology. His academic/research field is linked to motivational determinants in sport and exercise and behavioral change, with a special focus on sedentary behavior, physical activity, healthy lifestyles, well-being, exercise adherence, sport dropout, and persistence.

\section{ORCID}

Filipe Rodrigues (D) http://orcid.org/0000-0003-1327-8872

Diogo Santos Teixeira (D) http://orcid.org/0000-0003-4587-5903

Luis Cid (D) http://orcid.org/0000-0001-8156-3291

Bruno Travassos (D) http://orcid.org/0000-0002-2165-2687

Diogo Monteiro (D) http://orcid.org/0000-0002-7179-6814

\section{References}

Atwater, L., Ostroff, C., Yammarino, F., \& Fleenor, J. (1998). Self-other agreement: Does it really matter? Personnel Psychology, 51(3), 577-598. https://doi.org/10.1111/j.1744-6570.1998.tb00252.x 
Bartholomew, K., Ntoumanis, N., Ryan, R., Bosch, J., \& Thogersen-Ntoumani, C. (2011). Selfdetermination theory and diminished functioning: The role of interpersonal control and psychological need thwarting. Personality \& Social Psychology Bulletin, 37(11), 1459-1473. https:// doi.org/10.1177/0146167211413125

Bartholomew, K., Ntoumanis, N., Ryan, R., \& Thogersen-Ntoumani, C. (2011). Psychological need thwarting in the sport context: Assessing the darker side of athletic experience. Journal of Sport \& Exercise Psychology, 33(1), 75-102. https://doi.org/10.1123/jsep.33.1.75

Bhavsar, N., Bartholomew, K., Quested, E., Gucciardi, D. F., Thøgersen-Ntoumani, C., Reeve, J., Reeve, J., Sarrazin, P., \& Ntoumanis, N. (2020). Measuring psychological need states in sport: Theoretical considerations and a new measure. Psychology of Sport and Exercise, 47, 101617. https://doi.org/10.1016/j.psychsport.2019.101617

Bidee, J., Vantilborgh, T., Pepermans, R., Griep, Y., \& Hofmans, J. (2016). Temporal dynamics of need satisfaction and need frustration. Two sides of the same coin? European Journal of Work and Organizational Psychology, 25(6), 900-913. https://doi.org/10.1080/1359432X.2016.1176021

Biddle, S. (2016). Physical activity and mental health: Evidence is growing. World Psychiatry : Official Journal of the World Psychiatric Association (WPA), 15(2), 176-177. https://doi.org/10. 1002/wps.20331

Cohen, S., Reeve, J., Lee, Y., Ntoumanis, N., Gillet, N., Kim, B., \& Song, Y. (2019). Expanding autonomy psychological need states from two (satisfaction, frustration) to three (dissatisfaction): A classroom-based intervention study. Journal of Educational Psychology, 111(4), 685-702. https://doi.org/10.1037/edu0000306

Cid, L., Monteiro, D., Teixeira, D., Teques, P., Alves, S., Moutão, J., Silva, M., \& Palmeira, A. (2018). The behavioral regulation in exercise questionnaire (BREQ-3) Portuguese-version: Evidence of reliability, validity and invariance across gender. Frontiers in Psychology, 9, 1940. https://doi.org/10.3389/fpsyg.2018.01940

Cohen, J., Cohen, P., West, S., \& Aiken, L. (2003). Applied multiple regression/correlation analysis for the behavioral sciences (3rd ed.). Lawrence Erlbaum Associates Publishers. ISBN: 9780805822236.

Costa, S., Ntoumanis, N., \& Bartholomew, K. (2015). Predicting the brighter and darker sides of interpersonal relationships: Does psychological need thwarting matter? Motivation and Emotion, 39(1), 11-24. https://doi.org/10.1007/s11031-014-9427-0

Deci, E., \& Ryan, R. (2008). Self-determination theory: A macro theory of human motivation, development, and health. Canadian Psychology/Psychologie Canadienne, 49(3), 182-185. https:// doi.org/10.1037/a0012801

Edwards, J. (2007). Polynomial regression and response surface methodology. In: C. Ostroff \& A. Judge (Eds.), Perspectives on organizational fit (pp. 361-372). Jossey-Bass.

Eurobarometer. (2018). Special eurobarometer 472 - sport and physical activity (pp. 1-133). Eurobarometer.

García-González, L., Sevil, J., Abós, A., Aelterman, N., \& Haerens, L. (2019). The role of task and ego-oriented climate in explaining students' bright and dark motivational experiences in physical education. Physical Education and Sport Pedagogy, 24(4), 344-358. https://doi.org/10.1080/ 17408989.2019.1592145

Gunnell, K., Crocker, P., Wilson, P., Mack, D., \& Zumbo, B. (2013). Psychological need satisfaction and thwarting: A test of basic psychological needs theory in physical activity contexts. Psychology of Sport and Exercise, 14(5), 599-607. https://doi.org/10.1016/j.psychsport.2013.03. 007

Guthold, R., Stevens, G., Riley, L., \& Bull, F. (2018). Worldwide trends in insufficient physical activity from 2001 to 2016: A pooled analysis of 358 population-based surveys with 1.9 million participants . The Lancet. Global Health, 6(10), e1077-e1086.https://doi.org/10.1016/S2214109X(18)30357-7

Haerens, L., Aelterman, N., Vansteenkiste, M., Soenens, B., \& Petegem, S. (2015). Do perceived autonomy-supportive and controlling teaching relate to physical education students' motivational experiences through unique pathways? Distinguishing between the bright and dark side 
of motivation. Psychology of Sport and Exercise, 16(P3), 26-36. https://doi.org/10.1016/j.psychsport.2014.08.013

Howard, J., Gagne, M., \& Bureau, J. (2017). Testing a continuum structure of self-determined motivation: A meta-analysis. Psychological Bulletin, 143(12), 1346-1377. https://doi.org/10. 1037/bul0000125

IBM. (2017). IBM SPSS statistics for windows (version 25). IBM CORP.

Loyen, A., Van Hecke, L., Verloigne, M., Hendriksen, I., Lakerveld, J., Steene-Johannessen, J., Vuillemin, A., Koster, A., Donnelly, A., Ekelund, U., Deforche, B., Bourdeaudhuij, I., Brug, J., Ploeg, H., \& Dedipac, C., on behalf of the DEDIPAC consortium (2016). Variation in population levels of physical activity in European adults according to cross-European studies: A systematic literature review within DEDIPAC. International Journal of Behavioral Nutrition and Physical Activity, 13(1), 72. https://doi.org/10.1186/s12966-016-0398-2

Muthén, L., \& Muthén, B. (2010). Mplus User's Guide. Los Angeles, CA: Muthén \& Muthén.

Ntoumanis, N., Ng, J., Prestwich, A., Quested, E., Hancox, J. E., Thøgersen-Ntoumani, C., Deci, E., Ryan, R., Lonsdale, C., \& Williams, G. (2020). A meta-analysis of self-determination theory-informed intervention studies in the health domain: Effects on motivation, health behavior, physical, and psychological health. Health Psychology Review, 1-31. https://doi.org/10.1080/ 17437199.2020.1718529

Ntoumanis, N., Thøgersen-Ntoumani, C., Quested, E., \& Hancox, J. (2017). The effects of training group exercise class instructors to adopt a motivationally adaptive communication style. Scandinavian Journal of Medicine \& Science in Sports, 27(9), 1026-1034. https://doi.org/10. $1111 /$ sms. 12713

Raykov, T., Gabler, S., \& Dimitrov, D. (2016). Maximal reliability and composite reliability: Examining their difference for multicomponent measuring instruments using latent variable modeling. Structural Equation Modeling: A Multidisciplinary Journal, 23(3), 384-391. https:// doi.org/10.1080/10705511.2014.966369

Rhodes, R., Janssen, I., Bredin, S., Warburton, D., \& Bauman, A. (2017). Physical activity: Health impact, prevalence, correlates and interventions. Psychology \& Health, 32(8), 942-975. https:// doi.org/10.1080/08870446.2017.1325486

Rocchi, M., \& Pelletier, L. (2018). How does coaches reported interpersonal behavior align with athletes' perceptions? Consequences for female athletes' psychological needs in sport. Sport, Exercise, and Performance Psychology, 7(2), 141-154. https://doi.org/10.1037/spy0000116

Rodrigues, F., Bento, T., Cid, L., Pereira Neiva, H., Teixeira, D., Moutão, J., Marinho, D., \& Monteiro, D. (2018). Can interpersonal behavior influence the persistence and adherence to physical exercise practice in adults? A systematic review. Frontiers in Psychology, 9, 2141. https://doi.org/10.3389/fpsyg.2018.02141

Rodrigues, F., Hair, J., Neiva, H. P., Teixeira, D. S., Cid, L., \& Monteiro, D. (2019). The Basic Psychological Need Satisfaction and Frustration Scale in Exercise (BPNSFS-E): Validity, reliability, and gender invariance in Portuguese exercisers. Perceptual and Motor Skills, 126(5), 949-972. https://doi.org/10.1177/0031512519863188

Rodrigues, F., Teixeira, D., Neiva, H., Cid, L., \& Monteiro, D. (2020). The bright and dark sides of motivation as predictors of enjoyment, intention, and exercise persistence. Scandinavian Journal of Medicine \& Science in Sports, 30(4), 787-800. https://doi.org/10.1111/sms.1361

Ryan, R., \& Deci, E. (2017). Self-determination theory. Basic psychological needs in motivation, development, and wellness. Guilford Press. ISBN: 9781462538966.

Ryan, R., \& Deci, E. (2019). Brick by brick: The origins, development, and future of self-determination theory. In Advances in motivation science (Vol. 6, pp. 111-156). Elsevier. https://doi. org/10.1016/bs.adms.2019.01.001

Ryan, R., \& Deci, E. (2020). Intrinsic and extrinsic motivation from a self-determination theory perspective: Definitions, theory, practices, and future directions. Contemporary Educational Psychology, 61, 101860. https://doi.org/10.1016/j.cedpsych.2020.101860

Shanlock, L., Baran, B., Gentry, W., Pattison, S., \& Heggestad, E. (2010). Polynomial regression with response surface analysis: A powerful approach for examining moderation and 
overcoming limitations of difference scores. Journal of Business and Psychology, 25(4), 543-554. https://doi.org/10.1007/s10869-010-9183-4

Teixeira, P., Carraça, E., Markland, D., Silva, M., \& Ryan, R. (2012). Exercise, physical activity, and self-determination theory: A systematic review. International Journal of Behavioral Nutrition \& Physical Activity, 9, 78. https://doi.org/10.1186/1479-5868-9-78

Teixeira, D., Marques, M., \& Palmeira, A. (2018). Associations between affect, basic psychological needs and motivation in physical activity contexts: Systematic review and meta-analysis. Revista Iberoamericana de Psicologia Del Ejercicio y el Deporte, 13(2), 225-233.

Teixeira, D., Pelletier, L., Monteiro, D., Rodrigues, F., Moutão, J., Marinho, D., \& Cid, L. (2020). Motivational patterns in persistent swimmers: A serial mediation analysis. European Journal of Sport Science, 20(5), 660-669. https://doi.org/10.1080/17461391.2019.1675768

Teixeira, D., Silva, M., \& Palmeira, A. (2018). How does frustration make you feel? A motivational analysis in exercise context. Motivation and Emotion, 42(3), 419-428. https://doi.org/10. 1007/s11031-018-9690-6

Tóth-Király, I., Bőthe, B., Orosz, G., \& Rigó, A. (2020). On the importance of balanced need fulfillment: A person-centered perspective. Journal of Happiness Studies, 21(6), 1923-1944. https://doi.org/10.1007/s10902-018-0066-0

Vansteenkiste, M., \& Ryan, R. M. (2013). On psychological growth and vulnerability: Basic psychological need satisfaction and need frustration as a unifying principle. Journal of Psychotherapy Integration, 23(3), 263-280. https://doi.org/10.1037/a0032359

Vansteenkiste, M., Ryan, R. M., \& Soenens, B. (2020). Basic psychological need theory: Advancements, critical themes, and future directions. Motivation and Emotion, 44(1), 1-31. https://doi.org/10.1007/s11031-019-09818-1

Warburton, D., \& Bredin, S. (2017). Health benefits of physical activity: A systematic review of current systematic reviews. Current Opinion in Cardiology, 32(5), 541-556. https://doi.org/10. 1097/HCO.0000000000000437

Warburton, V., Wang, J., Bartholomew, K., Tuff, R., \& Bishop, K. (2020). Need satisfaction and need frustration as distinct and potentially co-occurring constructs: Need profiles examined in physical education and sport. Motivation and Emotion, 44(1), 54-66. https://doi.org/10.1007/ s11031-019-09798-2 